XIV Simpósio Nacional de Sistemas Prediais

Gestão, Eficiência e Sustentabilidade

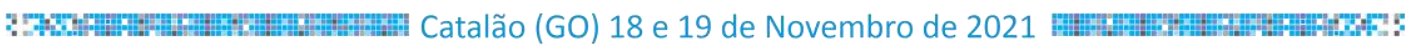

\title{
MORADIA ESTUDANTIL DO CERRADO (MUC) E OS CRITÉRIOS DE SUSTENTABILIDADE CONFORME CERTIFICAÇÃO SELO AZUL
}

\author{
Student housing of the cerrado (MUC) and sustainability criteria according to \\ Azul Seal certification \\ BENTO, Luciana de Andrade ${ }^{1}$; GONÇALVES, Rigley César Matias²; \\ MORAIS, Lucas Salomão Rael de ${ }^{3}$; PAULA, Heber Martins de $^{4}$
}

Recebido em 05 de agosto de 2021, aprovado em 06 de setembro de 2021, publicado em 18 de novembro de 2021

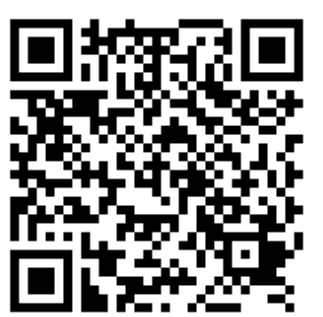

Palavras-chave:

Construção sustentável;

Sustentabilidade;

Selo Casa Azul.

Keywords:

Sustainable

construction;

Sustainability;

Blue seal certification.
RESUMO: A pretensão de uma indústria construtiva mais sustentável reflete na adoção de condutas como a minimização do consumo de matérias-primas, otimização dos recursos naturais e da utilização de novas e diversas tecnologias construtivas que possam reduzir os impactos ambientais gerados na produção de edificações. A Moradia Universitária do Cerrado (MUC), moradia estudantil, pertencente à Universidade Federal de Catalão (Em implantação) foi construída pleiteando atender vários critérios, de modo a garantir a sustentabilidade desde a fase de projetos até a pós-ocupação do edifício. Visando mensurar as práticas sustentáveis das construções a Caixa Econômica Federal, lançou o programa Selo Casa Azul + CAIXA, estabelecendo critérios e verificando a gradação em quatro níveis (bronze, prata, azul e diamante). Ante ao exposto, o presente trabalho tem por objetivo verificar, caso fosse possível a certificação de obras públicas no programa, em qual gradação se enquadra a MUC, conforme os critérios estabelecidos pelo Selo. $O$ estudo tem o intuito de demonstrar as beneficies desse tipo de construção e a conscientização da comunidade acadêmica quanto a essa vertente. Após análises dos parâmetros estabelecidos pelo programa, conferiu-se o Selo Bronze para a construção, sendo possível a gradação Prata, caso seja implantadas novas atividades após a ocupação do prédio.

ABSTRACT: The intention of a more sustainable construction industry is reflected in the adoption of behaviors such as minimizing the consumption of raw materials, optimizing natural resources and the use of new and diverse construction technologies that can reduce the environmental impacts generated in the production of buildings. The University House of Cerrado (MUC), a student house belonging to the Federal University of Catalão, was built to meet several criteria, in order to ensure sustainability from the design phase to the post-occupancy of the building. Aiming to measure sustainable construction practices, Caixa Econômica Federal launched the Casa Azul + CAIXA Seal program, establishing criteria and verifying the gradation in four levels (bronze, silver, blue and diamond). In view of the above, the present work aims to verify, if it were possible to certify public works in the program, in which grade the MUC fits, according to the criteria established by the Seal. The study aims to demonstrate the benefits of this type of construction and the awareness of the academic community regarding this aspect. After analyzing the parameters established by the program, the Silver Seal was awarded for the construction, with the possibility of a Gold grading, if new activities are implemented after the occupation of the building.

\footnotetext{
CONTATO DOS AUTORES:

${ }^{1}$ BENTO, Luciana de Andrade: Universidade Federal de Catalão, luciana_bento@ufcat.edu.br.

${ }^{2}$ GONÇALVES, Rigley César Matias: Universidade Federal de Catalão, rigley.matias@gmail.com.

${ }^{3}$ MORAIS, LUCAS Salomão Rael de: Universidade Federal de Catalão, lucas.salomao@ufg.br.

${ }^{4}$ PAULA, Heber Martins de: Universidade Federal de Catalão,heberdepaula@ufcat.edu.br.
} 


\section{INTRODUÇÃO}

A construção civil se caracteriza como uma atividade causadora de grandes impactos ambientais, uma vez que consome muitos recursos naturais, gera grande volume de resíduos e tem um consumo energético elevado. Diante desse cenário, surge a construção sustentável, visando minimizar os impactos gerados por esse setor da indústria. Pereira (2016) aponta que esse modelo de construção se cerca de atividades que empregam o uso inteligente de materiais e tecnologias, reduzem o consumo de água e energia e faz uso do reaproveitamento dos resíduos gerados pela construção. No âmbito econômico, as edificações que possuem alto desempenho necessitam de um maior investimento inicial, contudo, esperam-se menores custos operacionais, visando um retorno financeiro na durabilidade e conforto proporcionado pelo projeto.

A oferta de edifícios certificados como "'verdes" vem aumentando, devido a maior atenção do setor privado à construções com eficiência energética e potencial de redução da emissão de carbono. Existem várias certificações espalhadas pelo mundo que verificam a sustentabilidade de uma construção.

Chegut, Eichholtz e Kok (2013) trazem que em 1990 o Reino Unido foi o primeiro a introduzir uma ferramenta de avaliação para medir o impacto ambiental de um edifício, o Método de Avaliação Ambiental BRE (BREEAM). Nos Estados Unidos, a certificação de edifícios é realizada pela Liderança em Energia e Projeto Ambiental (LEED), sendo essa certificação a mais disseminada no território brasileiro. No Brasil, existe a certificação nomeada de Selo Casa Azul + CAIXA, a qual é um instrumento de classificação socioambiental destinada a propostas de empreendimentos habitacionais que adotem soluções eficientes na concepção, execução, uso, ocupação e manutenção das edificações. Atualmente, a adesão à certificação Selo Casa Azul + CAIXA é voltada para a fase de projetos novos em fase de análise ou já analisados para a contratação, apresentando limitações para adesão de órgãos públicos de todas as esferas de poder, edifícios de uso não habitacional e edificações já em fase de construção ou recém-entregues, visto que para a adesão desse certificado é necessário dar entrada junto à Caixa Econômica Federal ainda em fase de projeto, limitando-se a conjuntos habitacionais.

De acordo com Santos (2002) os sistemas prediais relacionam-se com higiene e saúde, porém, com o conforto do usuário. Dada a relevância dos sistemas prediais dentro de uma edificação e seus reflexos na segurança, conforto e satisfação do usuário, é observada a exigência de atendimento a diversos critérios obrigatórios relacionados à melhoria da qualidade, desempenho e eficiência das instalações prediais, como por exemplo, o uso de dispositivos economizadores de água e energia elétrica e exigência de medições individualizadas nas unidades, além de itens não obrigatórios que incentivam a prática da sustentabilidade nesses sistemas, como a implantação de sistema de aquecimento solar, geração de energia renovável, reuso de águas cinzas e aproveitamento de águas pluviais.

Face ao exposto, o presente trabalho consiste na avaliação da Moradia Universitária do Cerrado (MUC), uma edificação pública federal recém-construída, para a quantificação das atividades sustentáveis previstas no projeto, construção, manutenção e ocupação, além de intervenções sugeridas à edificação, relacionadas ao atendimento dos critérios estabelecidos pela certificação Selo Casa Azul + Caixa, verificando o grau de sustentabilidade que seria alcançado pela edificação caso a certificação possibilitasse que um empreendimento com essas características pleiteasse o selo. A certificação escolhida para enquadramento da 
edificação se deu, devido a ser uma certificação legitimamente brasileira, com critérios semelhantes às outras certificações mais populares.

\section{METODOLOGIA}

O Selo Casa Azul + Caixa, principal objeto de estudo deste trabalho, trata-se de um instrumento de certificação baseado na classificação socioambiental no tocante a soluções sustentáveis que englobem a concepção, execução, uso, ocupação e manutenção de edificações com fins habitacionais. Seu principal objetivo é dar reconhecimento e incentivar a implementação de soluções ambientalmente corretas nos processos que circundam o desenvolvimento de uma edificação.

Para receber a certificação a construtora, incorporadora, poder público, associação ou entidade representativa do conjunto de habitação deve apresentar à Caixa Econômica, ainda em fase de projeto, a documentação referente ao empreendimento para, ao fim da construção, o órgão federal vistoriar o local e identificar a existência dos aspectos sustentáveis e consolidar a emissão do selo de acordo com a pontuação obtida.

A classificação é dividida entre quatro níveis de gradação, Quadro 1, consistindo em bronze, prata, ouro e diamante, sendo necessários 50,60, 80 e 100 pontos para atingir cada uma das posições, respectivamente.

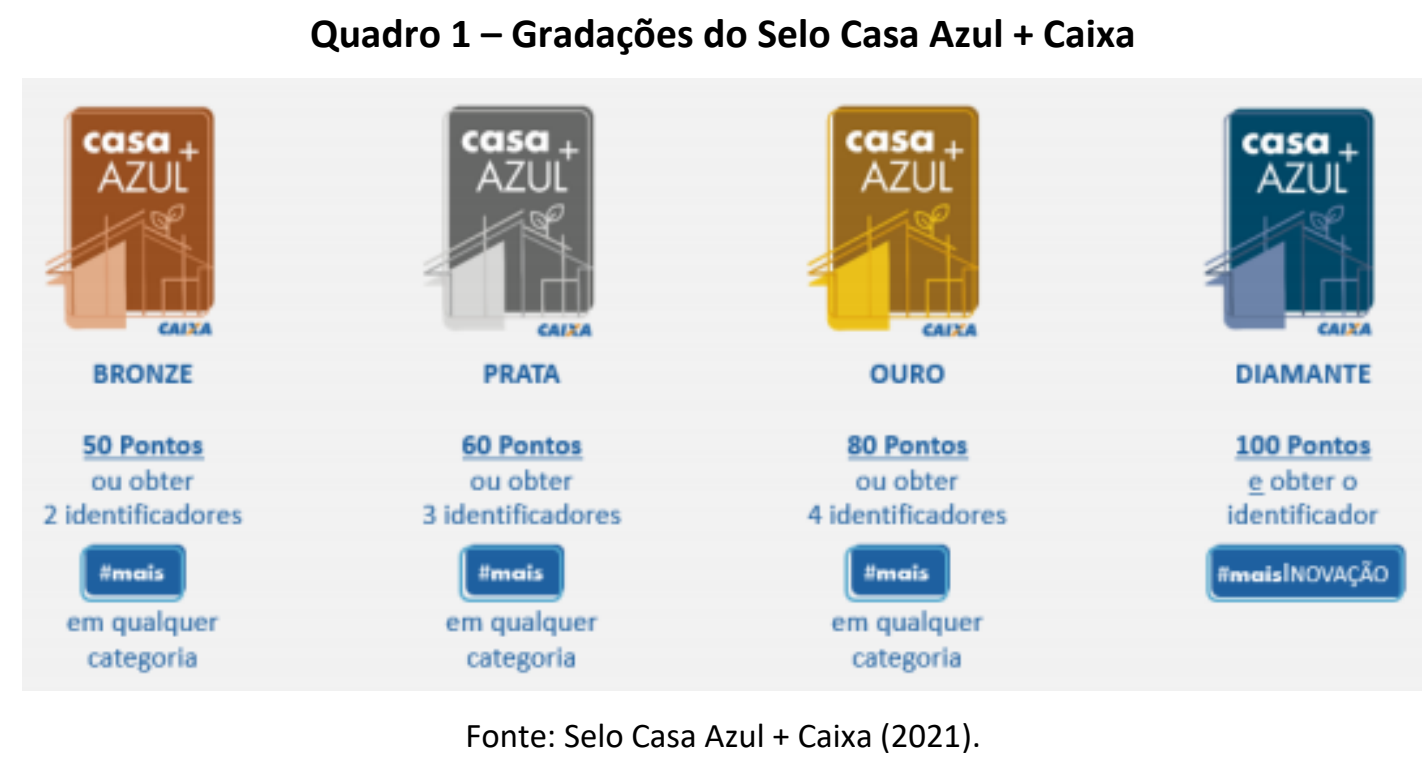

As categorias de avaliação a serem observadas dizem respeito à qualidade urbana e bem estar na edificação, eficiência energética e conforto ambiental, gestão eficiente da água, produção sustentável, desenvolvimento social e inovações. Cada categoria é subdividida entre critérios obrigatórios e não obrigatórios, com um total de 49, sendo os obrigatórios imprescindíveis para a obtenção de qualquer gradação.

Ainda, caso o projeto se destaque em apenas uma categoria ou outra, é possível que a construção pleiteie apenas um identificador, que define o projeto como sustentável em relação a determinado tema.

Desta forma, é aplicado o Selo Casa Azul + Caixa na MUC e avaliado quais são as categorias e critérios atendidos pelo empreendimento, determinando qual é a pontuação e, consequentemente, a gradação que a MUC teria de acordo com o manual. 
Cumpre-se, portanto, com os procedimentos metodológicos adotados, o objetivo proposto de avaliar a sustentabilidade na MUC e contribuir com o estudo da sustentabilidade na construção civil, o que possibilita dar continuidade aos estudos do tema propriamente dito.

\section{RESULTADOS}

A Moradia Universitária do Cerrado (MUC), Figura 1, consiste em um prédio destinado à moradia estudantil, pertencente à Universidade Federal de Catalão (em implantação), onde o projeto foi desenvolvido pleiteando práticas sustentáveis, desde a construção até a pósocupação, como por exemplo: implantação de medição individualizada de água, energia e gás; aquecimento solar de água, futura implantação de usina fotovoltaica.

Figura 1 - Visão geral do empreendimento avaliado

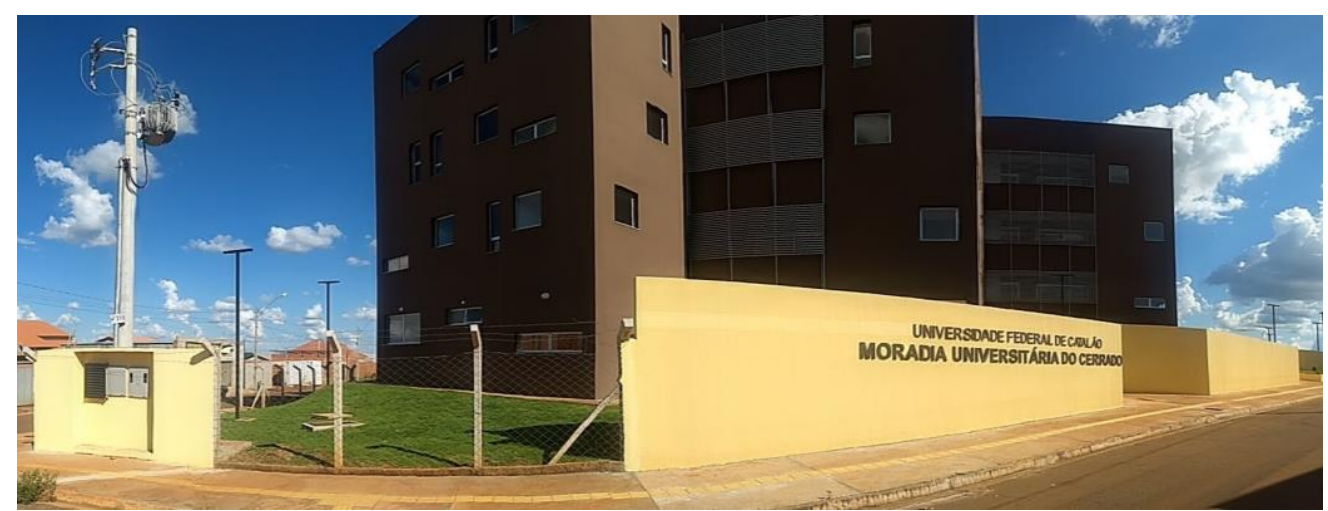

Fonte: Autores (2021).

Ante ao exposto, a MUC refere-se a uma edificação pública, com o objetivo de se tornar uma moradia estudantil que contempla a sustentabilidade nas fases de projeto, construção, uso, ocupação e manutenção.

A obra já atende diversos itens determinados pelos critérios estabelecidos pelo Selo, sendo estes ilustrados no Quadro 2. O mesmo demonstra a gradação da moradia estudantil, que pelo total de pontos alcançados, superaria a gradação BRONZE, porém com alguns critérios obrigatórios não atendidos. 
Quadro 2 - Pontuação MUC - Selo Azul Caixa

\begin{tabular}{|c|c|c|c|c|c|}
\hline Item & Descrição & Pontuação & Situação & Obrigatório & Observação \\
\hline 1.1 & $\begin{array}{l}\text { Qualidade e } \\
\text { Infraestrutura no } \\
\text { Espaço Urbano }\end{array}$ & 4 & OK & Sim & $\begin{array}{l}\text { - Acesso a rede de abastecimento de água } \\
\text { potável, sistemas de esgotamento sanitário } \\
\text { com tratamento em ETE, rede de drenagem } \\
\text { de águas pluviais, sistema de coleta } \\
\text { domiciliar de resíduos sólidos, rede de } \\
\text { energia elétrica e iluminação pública; } \\
\text { - Via de acesso pavimentada; } \\
\text { - Dispõe de uma linha de transporte público } \\
\text { com parada distando a } 200 \text { metros do } \\
\text { empreendimento; } \\
\text { - Distante a 1,00 km de rede de comércio, } \\
\text { 2,00 km de escola de ensino fundamental, } \\
\text { 2,5 km da UPA municipal e } 1,5 \text { km de } \\
\text { parque com pista de caminhada. }\end{array}$ \\
\hline 1.2 & $\begin{array}{l}\text { Relação com o } \\
\text { Entorno: } \\
\text { Interferências e } \\
\text { Impactos no } \\
\text { Empreendimento }\end{array}$ & 3 & Não OK & Sim & $\begin{array}{l}\text { Empreendimento a 1,70 km da rodovia GO- } \\
\text { 210. Mitigação do problema: uso de } \\
\text { esquadrias da marca Alcoa, linha Inova com } \\
\text { espessura de vidro de } 6 \mathrm{~mm} \text { que atende a } \\
\text { classe de ruído I em nível de desempenho } \\
\text { intermediário conforme tabela F.9 da ABNT } \\
\text { NBR 15575-4:2013. }\end{array}$ \\
\hline 1.7 & Paisagismo & 3 & OK & Não & $\begin{array}{l}\text { Implantado conforme planta de situação } \\
\text { detalhes do paisagismo. }\end{array}$ \\
\hline 1.9 & $\begin{array}{l}\text { Adequação às } \\
\text { Condições do } \\
\text { Terreno }\end{array}$ & 3 & OK & Não & $\begin{array}{l}\text { Item atendido conforme planta de situação } \\
\text { e implantação }(9 / 14) \text {, onde é apresentado a } \\
\text { existência de diversos níveis de construção } \\
\text { na área do terreno, visando aproveitar o } \\
\text { perfil natural do terreno. }\end{array}$ \\
\hline 2.2 & $\begin{array}{l}\text { Desempenho } \\
\text { Térmico e } \\
\text { Lumínico }\end{array}$ & 4 & OK & Sim & $\begin{array}{l}\text { Conforme projetos de arquitetura, foram } \\
\text { atendidos todos os critérios mínimos de } \\
\text { áreas de abertura e ventilação conforme } \\
\text { legislação municipal que estabelece } 1 / 6 \text { da } \\
\text { área do piso para compartimentos de } \\
\text { permanência prolongada e } 1 / 8 \text { da área do } \\
\text { piso para compartimentos de permanência } \\
\text { transitória. }\end{array}$ \\
\hline 2.3 & \begin{tabular}{|l|} 
Dispositivos \\
Economizadores \\
de Energia \\
\end{tabular} & 2 & OK & Sim & $\begin{array}{l}\text { Itens implantados conforme projeto de } \\
\text { instalações elétricas (minuteiras e lâmpadas } \\
\text { de auto desempenho LED). }\end{array}$ \\
\hline 2.4 & \begin{tabular}{|l|} 
Medição \\
Individualizada de \\
Gás \\
\end{tabular} & 3 & OK & Sim & Implantado conforme projeto de GLP. \\
\hline 2.6 & $\begin{array}{l}\text { Iluminação } \\
\text { Natural de Áreas } \\
\text { Comuns }\end{array}$ & 3 & OK & Não & $\begin{array}{l}\text { Item atendido conforme projeto de } \\
\text { arquitetura com aberturas superiores a } \\
45 \% \text { da área do piso da área comum } \\
\text { (corredores). }\end{array}$ \\
\hline
\end{tabular}


Quadro 2 - Pontuação MUC - Selo Azul Caixa (Continuação)

\begin{tabular}{|c|c|c|c|c|c|}
\hline Item & Descrição & Pontuação & Situação & Obrigatório & Observação \\
\hline 2.7 & $\begin{array}{l}\text { Sistema de } \\
\text { Aquecimento } \\
\text { Solar }\end{array}$ & 4 & OK & Não & \begin{tabular}{|l} 
Item existente conforme projetos \\
hidráulicos da obra. Todos os chuveiros \\
existentes na obra tem aquecimento da \\
água realizado por painéis solares. \\
\end{tabular} \\
\hline 3.2 & \begin{tabular}{|l|} 
Medição \\
Individualizada de \\
Água
\end{tabular} & 3 & OK & Sim & $\begin{array}{l}\text { Implantado conforme projetos } \\
\text { hidrossanitários. }\end{array}$ \\
\hline 3.3 & Áreas Permeáveis & 4 & OK & Sim & \begin{tabular}{|l|} 
Implantado conforme projeto de \\
arquitetura e planta de implantação.
\end{tabular} \\
\hline 3.6 & \begin{tabular}{|l|} 
Retenção / \\
Infiltração de \\
Águas Pluviais \\
\end{tabular} & 3 & OK & Não & $\begin{array}{l}\text { Existente conforme projeto de drenagem } \\
\text { de águas pluviais poço de infiltração com } \\
\text { volume de } 3,92 \mathrm{~m}^{3} \text {. } \\
\end{array}$ \\
\hline 4.1 & \begin{tabular}{|l|} 
Gestão de \\
Resíduos da \\
Construção e \\
Demolição
\end{tabular} & 3 & OK & Sim & $\begin{array}{l}\text { Implantado conforme item } 37 \text { das } \\
\text { obrigações da Contratada previsto no Plano } \\
\text { de Trabalho e Caderno de Especificações } \\
\text { Técnicas. }\end{array}$ \\
\hline 4.2 & $\begin{array}{l}\text { Fôrmas e Escoras } \\
\text { Reutilizáveis }\end{array}$ & 3 & OK & Sim & $\begin{array}{l}\text { Executado conforme previsto em planilha } \\
\text { orçamentária: formas do tipo compensada } \\
\text { e plastificada com } 7 \text { utilizações. }\end{array}$ \\
\hline 4.3 & $\begin{array}{l}\text { Madeira } \\
\text { Certificada }\end{array}$ & 1 & OK & Sim & $\begin{array}{l}\text { Implantado conforme item } 36 \text { das } \\
\text { obrigações da Contratada previsto no Plano } \\
\text { de Trabalho e Caderno de Especificações } \\
\text { Técnicas }\end{array}$ \\
\hline 5.3 & $\begin{array}{l}\text { Inclusão de } \\
\text { Trabalhadores e } \\
\text { Fornecedores } \\
\text { Locais }\end{array}$ & 1 & OK & Não & $\begin{array}{l}\text { Durante toda a execução da obra, foi dado } \\
\text { preferência para a contratação de mão de } \\
\text { obra de moradores da cidade e de } \\
\text { fornecedores locais, como por exemplo } \\
\text { para o fornecimento de concreto usinado. }\end{array}$ \\
\hline 5.9 & $\begin{array}{l}\text { Ações de } \\
\text { Integração Social } \\
\text { na Comunidade }\end{array}$ & 1 & OK & Não & $\begin{array}{l}\text { Existem ações da Pró-Reitoria de Políticas } \\
\text { Estudantis que realizam a integração dos } \\
\text { estudantes vinculados com projetos de } \\
\text { extensão da universidade. Essas ações } \\
\text { serão implantadas aos alunos residentes da } \\
\text { MUC. }\end{array}$ \\
\hline 5.10 & $\begin{array}{l}\text { Apoio na } \\
\text { Manutenção Pós- } \\
\text { Ocupação }\end{array}$ & 3 & OK & Não & $\begin{array}{l}\text { Existe na estrutura da universidade o } \\
\text { DINFRA - Departamento de Infraestrutura, } \\
\text { que dá apoio a manutenção da } \\
\text { universidade e que fará a gestão da } \\
\text { manutenção da MUC. }\end{array}$ \\
\hline 6.3 & \begin{tabular}{|l|} 
Sistemas \\
Eficientes de \\
Automação \\
Predial \\
\end{tabular} & 3 & OK & Não & $\begin{array}{l}\text { Implantado o sistema de medições remotas } \\
\text { de energia elétrica e água fria a partir de } \\
\text { software SMART32. }\end{array}$ \\
\hline 6.4 & Conectividade & 2 & OK & Não & $\begin{array}{l}\text { Executado projeto de cabeamento } \\
\text { estruturado com tomadas de dados em } \\
\text { todos os compartimentos do edifício. Sinal } \\
\text { de internet via WiFi previsto em toda a } \\
\text { edificação. }\end{array}$ \\
\hline & TOTAL & 56 & & & \\
\hline
\end{tabular}

Fonte: Autores (2021). 
O Quadro 3 apresenta algumas atividades que já se encontram em implantação no empreendimento ou de fácil implantação à edificação, o que atenderia todos os critérios obrigatórios da certificação e possibilitaria a gradação da edificação para o Selo PRATA, alcançando 74 pontos e a conquista de um identificador \#mais EficiênciaEnergética.

\section{Quadro 3 - Pontuação MUC - Em implantação e A implantar}

\begin{tabular}{|c|c|c|c|c|c|}
\hline Item & Descrição & Pontuação & Situação & Obrigatório & Observação \\
\hline 1.3 & Coleta Seletiva & 3 & A implantar & Sim & $\begin{array}{l}\text { Proposta de implantação no projeto de } \\
\text { arquitetura e memorial descritivo de espaço } \\
\text { físico de separação de materiais recicláveis } \\
\text { no empreendimento. }\end{array}$ \\
\hline 2.1 & $\begin{array}{l}\text { Orientação ao } \\
\text { Sol e Ventos }\end{array}$ & 3 & A implantar & Sim & $\begin{array}{l}\text { A edificação é localizada na Zona } \\
\text { Bioclimática } 6 \text {. Para os compartimentos } \\
\text { voltados para a face oeste, é proposta a } \\
\text { instalação do brise Aeroscreen Curvo Hunter } \\
\text { Douglas com barra de comando junto as } \\
\text { esquadrias. Ressalta-se que nas varandas já } \\
\text { existe um brise instalado junto a construção. }\end{array}$ \\
\hline 2.8 & $\begin{array}{l}\text { Geração de } \\
\text { Energia } \\
\text { Renovável } \\
\end{array}$ & 5 & $\begin{array}{l}\text { Em } \\
\text { implantação }\end{array}$ & Não & $\begin{array}{l}\text { A instalação de uma usina fotovoltaica na } \\
\text { área de } 230 \mathrm{~m}^{2} \text { de telhado disponível está } \\
\text { em fase de execução contratual. }\end{array}$ \\
\hline 3.1 & $\begin{array}{l}\text { Dispositivos } \\
\text { Economizadores } \\
\text { de Água }\end{array}$ & 3 & $\begin{array}{c}\text { Em } \\
\text { implantação }\end{array}$ & Sim & $\begin{array}{l}\text { Realização da troca das caixas de descarga } \\
\text { para equipamentos da linha Montana Hydro } \\
\text { Ecoline de duplo acionamento. A obra já } \\
\text { tem instalados arejadores nas torneiras e } \\
\text { registros reguladores de vazão em todos os } \\
\text { dispositivos. }\end{array}$ \\
\hline 5.1 & $\begin{array}{l}\text { Capacitação para } \\
\text { Gestão do } \\
\text { Empreendimento } \\
\end{array}$ & 2 & $\begin{array}{l}\text { Em } \\
\text { implantação }\end{array}$ & Sim & $\begin{array}{l}\text { Em implantação pela Pró-Reitoria de } \\
\text { Políticas Estudantis/UFCAT. }\end{array}$ \\
\hline 5.2 & \begin{tabular}{|l} 
Educação \\
Financeira e \\
Planejamento \\
Financeiro dos \\
Moradores
\end{tabular} & 2 & $\begin{array}{c}\text { Em } \\
\text { implantação }\end{array}$ & Sim & $\begin{array}{l}\text { Proposta de implantação de educação } \\
\text { financeira e planejamento aos futuros } \\
\text { moradores para a Pró-Reitoria de Políticas } \\
\text { Estudantis/UFCAT. }\end{array}$ \\
\hline & TOTAL & 18 & & & \\
\hline
\end{tabular}

Fonte: Autores (2021).

No âmbito de Eficiência Energética, visando à economia de energia elétrica e promovendo a geração de energia limpa, a edificação contempla dispositivos economizadores de energia, sistema de aquecimento solar, conforme Figura 2 e futura instalação de uma usina fotovoltaica na edificação. 


\section{Figura 2 - Placas de Aquecimento Solar}

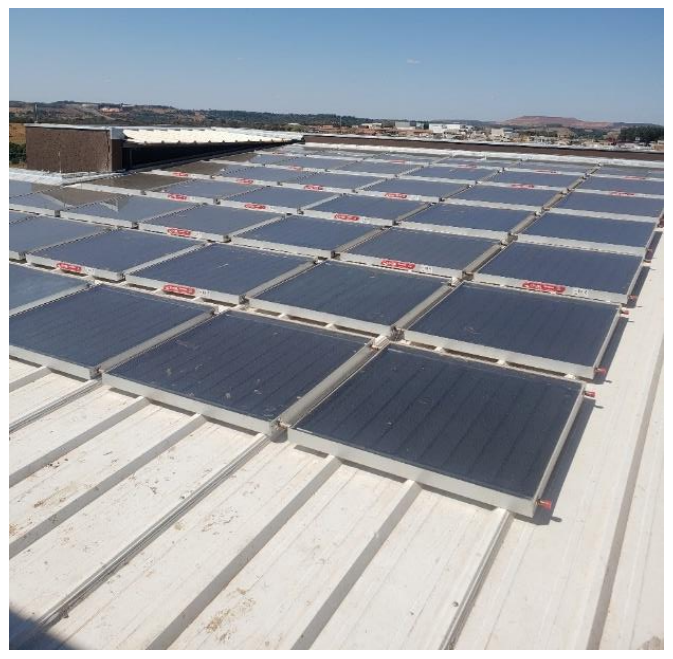

Fonte: Autores (2021).

Em relação ao paisagismo do empreendimento, foi pensado em projeto o plantio de vegetação gramínea que colabora com o bem estar dos moradores, além de contribuir com a quantidade de $\mathrm{CO}_{2}$ no ambiente, elevação da umidade e minimizando as chances de erosão do solo. É previsto ainda o plantio de vegetações típicas do cerrado no empreendimento que serão parte da composição paisagística do entorno. A Figura 3 mostra o paisagismo do local.

Figura 3 - Vegetação do local.

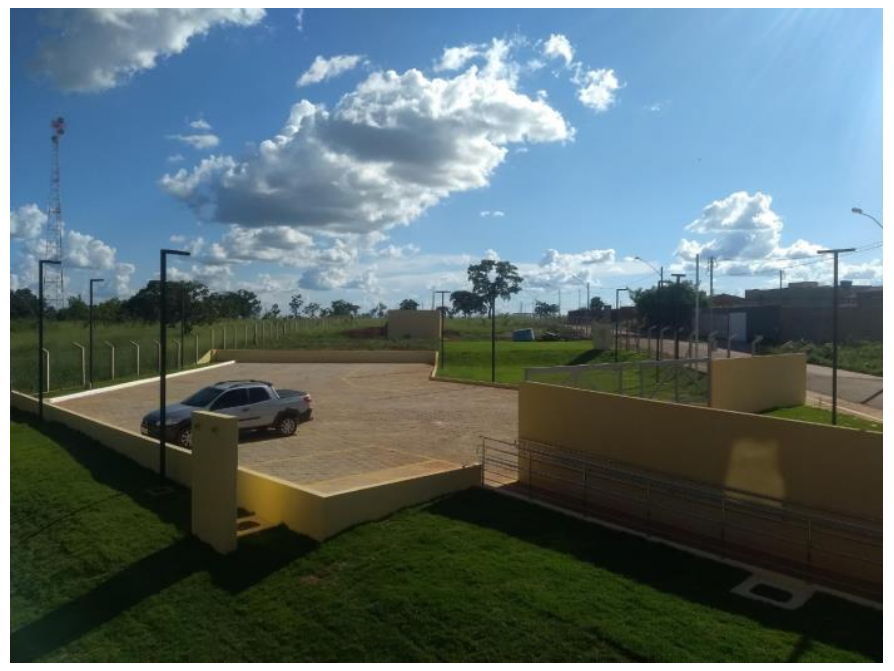

Fonte: Autores (2021).

No tocante ao relacionamento com o entorno, por se tratar de uma construção localizada a menos de $2 \mathrm{~km}$ de uma rodovia, conforme apresentado na Figura 4, a edificação não atende esse quesito. Como mitigação dessa pendência, ressalta-se que na obra foram instaladas esquadrias que apresentam propriedades de isolamento de som, evitando a poluição sonora dos usuários, conforme apresentado no Quadro 1. 


\section{Figura 4 - Distância da Casa do Estudante até a BR-050.}

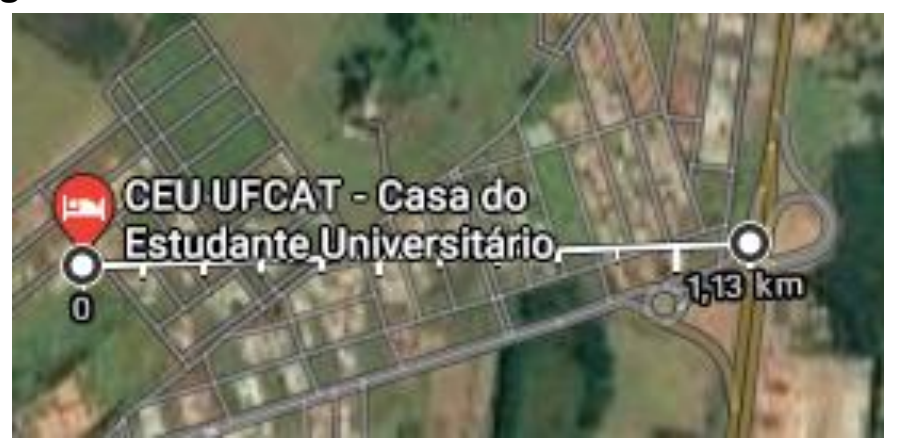

Fonte: Autores (2021).

A medição de energia, água e gás é individualizada para todos os apartamentos, artifício que facilita o controle de consumo por unidade e estimula um consumo racional e eficiente, além de proporcionar mais conforto e segurança aos usuários. A Figura 5 mostra os medidores de GLP.

Figura 5 - Medidores individuais de energia, gás e água na MUC.
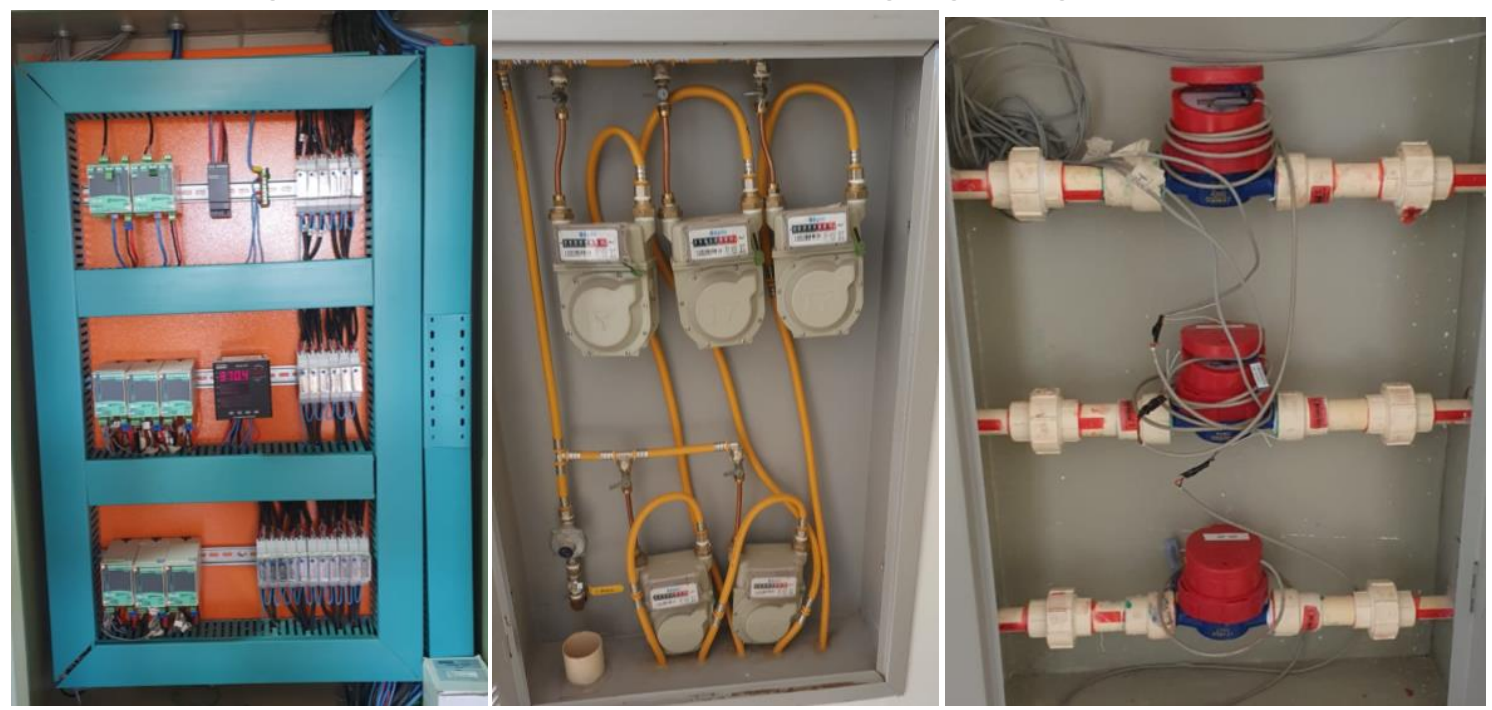

Fonte: Autores (2021).

\section{CONCLUSÕES}

É destaque, as ações já implantadas na obra referente à eficiência dos sistemas prediais que refletem em práticas sustentáveis proporcionando a redução de recursos naturais durante o uso e operação do edifício e nos custos de manutenção do empreendimento como a geração de energia renovável, aquecimento solar de água, sistemas de automação de medição de água e energia e uso de dispositivos economizadores.

A obra apresentada não pode ser certificada no Programa Selo Casa Azul + CAIXA devido a se tratar de obra pública federal já construída, voltada para moradia estudantil e não se enquadrar nos pré-requisitos iniciais do projeto. Além disso, a solicitação para receber a certificação necessita de duas etapas, sendo elas: Projetar e Habitar, onde a primeira delas sendo realizada na contratação da empresa e o formulário de intenção ser entregue antes do início da obra. Porém, observa-se que a edificação cumpre a maioria dos critérios mínimos exigidos pelo programa de certificação e com algumas intervenções de baixa 
complexidade, alcançaria o selo PRATA com destaque para ações voltadas para eficiência energética.

Portanto, a flexibilização de exigências mínimas no programa de certificação Selo Casa Azul + CAIXA possibilitaria um alcance maior de empreendimentos possíveis de certificação, como, por exemplo, edificações públicas diversas, em fase de construção ou passíveis de intervenções que possibilitem a expansão das práticas sustentáveis na construção civil e melhoria da eficiência dos sistemas prediais.

\section{REFERÊNCIAS}

ASSOCIAÇÃO BRASILEIRA DE NORMAS TÉCNICAS. NBR 15575-4: Edificações Habitacionais Desempenho Parte 5: Requisitos para os sistemas de vedações verticais internas e externas - SVVIE. Rio de Janeiro, 2013.

BRASIL. Lei no 13.634, de 20 de março de 2018. Cria a Universidade Federal de Catalão, por desmembramento da Universidade Federal de Goiás. Brasil, Disponível em: http://www.planalto.gov.br/ccivil_03/_ato2015-2018/2018/lei/l13634.htm. Acesso em: 29 jun. 2021.

(BRASIL), Caixa Econômica Federal (org.). Guia Selo Casa Azul + Caixa. Brasília: Caixa Econômica Federal, 2021. 008 v. Disponível em:<https://www.caixa.gov.br/Downloads/selo_casa_azul/guiaselo-casa-azul-caixa.pdf>. Acesso em: 08 jul. 2021.

CHEGUT, Andrea; EICHHOLTZ, Piet; KOK, Nils. Supply, Demand and the Value of Green Buildings. Urban Studies, [S.L.], v. 51, n. 1, p. 22-43, 16 maio 2013. SAGE Publications. http://dx.doi.org/10.1177/0042098013484526. Disponível em: https://journals-sagepubcom.ez49.periodicos.capes.gov.br/doi/full/10.1177/0042098013484526. Acesso em: 30 de jun. 2021.

PEREIRA, B. J. Sustentabilidade: um desafio para engenharia. Revista Instituto de Educação Tecnológica, Brasília, 2016. Disponível em: < http://www.techoje.com.br/site/techoje/categoria/detalhe_artigo/1693>. Data de acesso: 15 de jun. 2021.

SANTOS, Daniel Costa dos. Os sistemas prediais e a promoção da sustentabilidade ambiental. Ambiente Construído, Porto Alegre, v. 2, n. 4, p. 7-18, dez. 2002. Disponível em: https://seer.ufrgs.br/ambienteconstruido/article/view/3429/1847. Acesso em: 12 de jun. 2021. 